\title{
CRISTOBAL DE CASTILLEJO Y LOS AVATARES DE SU CELESTINA
}

\author{
Manuel Ferrer-Chivite \\ University College-Dublin
}

Uno de los objetivos que se propuso y que, como sabemos, viene realizando desde hace algún tiempo' el infatigable y laborioso editor de esta Celestinesca, es un índice recopilatorio de cuantas citas, referencias y comentarios se han hecho a y de Celestina a lo largo de toda la literatura y crítica posteriores. La información que sigue es mi propósito de contribuir con mi granito de arena en esa línea, amén de aprovechar la ocasión para algún pertinente comentario sobre la obra y el autor que en esta ocasión me ocupa.

De los más tempranos en recordar a Celestina citando sus rasgos y trapacerías fue Cristóbal de Castillejo, autor bastante más olvidado - y cuando no olvidado, no todo lo justamente tratado - de lo que debiera y se merece. Que se sepa, la primera edición conocida de su Sermón de amores - aparecida, entiéndase, como anónima - data de 1542, de acuerdo con el ejemplar que obra en la British Library. ${ }^{2}$ En su portada, se lee: «Sermon de amores | del maestro bue $[n]$ tala $[n]-\mid$ te llamado fray $\mathrm{Ni}-\mid$ del de la orden dl $\mid$ fristel.Agora $\mid$ nueuamente | Corregido y enme[n]dado | Año de. M. D. xlii.», sin pie de imprenta ni lugar. Que en la misma aparezca ese "nueuamente corregido y enmendado" ya nos sugiere la existencia de una anterior edición en la que hubieron de darse cuanto esas correcciones y enmiendas suponen, y algún dato más hay que nos asegura de ello.

Este texto de 1542 [desde ahora 42] está montado, todo a lo largo de él y sin excepción alguna, sobre quintillas de pie quebrado - métricamente,

1 J.T. Snow comenzó su labor con "Hacia una historia de la recepción de Celestina, 1499-1822,"Celestinesca 21 (1997), 115-172.

${ }^{2}$ Lleva signatura C.63.g.29,y puede verse facsímil en Arthur L.-F.Askins, ed., Pliegos poéticos españoles de la British Library, London (Siglo XVI), Madrid, Joyas bibliográficas, 1989, 4 vols. El facsímil en vol. 1. 
estrofa de cuatro octosílabos con un tetrasílabo final-; ello no obstante, dicho texto se cierra, sin más, en fol. $\mathrm{xx}^{\mathrm{v}}$, con tres octosílabos tras los que se lee "f Fin.», dejando, así, abruptamente trunca la correspondiente última quintilla. ${ }^{3}$ Anomalía que ya observó Foulché-Delbosc cuando transcribió una copia manuscrita de esa edición ${ }^{4}$ y que atestiguó en nota diciendo: «L'exemplaire de l'édition originale [...]était donc incomplet; les vers [...]se trouvaient sur le dernier feuillet, qui manquait à cet exemplaire». Supuso bien que «l'édition originale [...]était donc incomplet» pues que así lo atestiguaba la copia manuscrita de que se servía, pero no tan bien que «le dernier feuillet [...]manquait à cet exemplaire». Si hubiera podido ver esa 'édition originale' con cuya copia trabajaba - es decir, el ejemplar de la $\mathrm{BL}-{ }^{5}$ habría comprobado que el mismo, bajo los últimos versos truncados y ese «โFin.» presenta un grabado dejando, además, el resto de la hoja - más de la mitad en blanco, lo que le hubiera asegurado de que nadie había arrancado un 'dernier feuillet' o, lo que es lo mismo, que no era ese 42 el ejemplar mutilado sino un anterior original - una especie de Ur-Sermón, digamos - fuente y modelo del tal 42 y que el primero se limitaba a reproducir. ${ }^{6}$

Añádase que leyendo los vv. 2687 a $2800^{7}$ de este Sermón se comprueba que cuanto hace Castillejo con toda esa tirada es traducir libremente, repitiéndolo, todo el símil que entre el amante y el guerrero ya había elaborado Ovidio en sus Amores, I, $9 .{ }^{8}$ Ahora bien, ocurre, y como ya

${ }^{3}$ Véase la reproducción adjunta. La foliación es mía ya que en el texto sólo llega hasta a $\mathrm{x}$.

${ }^{4}$ Cf. «Deux œuvres de Cristóbal de Castillejo», Revue Hispanique 36 (1916), 489-620. El Sermón ocupa pp. 509-595 y en 502 ya nos informa de que transcribe una copia que en p. 616 confirma como manuscrita. La cita que a continuación recojo, en p. 620 .

${ }^{5}$ Como ya dice en p. 506, se limita a citar éste por Salvá, el cual, por su parte, nada comenta de esa irregularidad. Véase su Catálogo, I, p. 204, n526.

${ }^{6}$ Cuanto pueda haber tras todo esto - el cómo y el porqué de esa mutilación - no corresponde, ciertamente, a este trabajo. Lo dejo para una edición crítica que del texto vengo preparando.

${ }^{7}$ Doy la numeración por J. Domínguez Bordona, ed., Obras, Madrid, Ed. «La Lectura», 1926-28, 4 vols., (Clás. Cast., 72), I, pp. 3-105, edición de mayor accesibilidad y que, por otro lado, sigue la del hispanista francés - como dice su editor en xxxv). El primero, por su parte, completó su texto acudiendo a la edición de Adolfo de Castro de 1854 (Bibliotecade Autores Españoles 32) según se deduce tanto de lo que dice en p. 616 como de las siguientes notas.

${ }^{8}$ No que Castillejo fuera un plagiario, que ya comienza esa tirada con «Anda en guerra todo amante:/ no lo digo sólo yo,/ porque Ovidio lo escribió/ en verso más elegante/ y polido:/ habet sua castra Cupido/»? (vv. 2687-2692), un «Habet sua castra Cupido» que, por cierto, en el ?42 aparece como «a veces trata Cupido» (!), con una transcripción tan aberrante que algo indica sobre que no sea ese ?42 el original. Que, 
he señalado, que esa edición del 42 acaba, sin más, con el v. 2734, es decir, prácticamente en la misma mitad de esa reelaboración ovidiana de Castillejo. Si formalmente la quintilla abruptamente truncada nos asegura la existencia de un previo texto mutilado, contextualmente, esta anómala interrupción de toda una correspondiente paráfrasis, lo ratifica aún más si cabe.

Sentadas estas iniciales premisas, toca ya pasar a la extensa tirada con que Castillejo, por boca de su predicador, invoca a Celestina solicitando todo su favor y ayuda para poder llevar a buen cabo su labor sermoneadora; dice así: 9

f. a iiiir [col. a]
$\mathrm{Y}^{10}$ la madre Celestina
encomendando primero
la bolsa mas no el dinero
porque sabe ${ }^{12}$ de rapiña
bien ceuada
Mas por que fue fiel criada
desta propia voluntad
por su gran ${ }^{13}$ autoridad
la tomo por abogada
singular
Para que nos quieras ${ }^{14}$ dar
$\sin ^{15}$ gracia de bien decir,
a vosotros para oyr,

por otro lado, Ovidio era un santo muy de la devoción de Castillejo lo muestran no sólo las otras menciones de él en este mismo Sermón - desde v. 1703 y 2553 respectivamente - sino, y sobre todo, las traducciones que de sus fábulas mitológicas hizo, la de Acteón, la de Polifemo y Galatea y la de Píramo y Tisbe, traducciones que ahora pueden verse pulcramente editadas por Blanca Periñán, Cristóbal de Castillejo: Fábulas mitoloógicas, Viareggio-Lucca, M. Baroni, 1999.

${ }^{9}$ Son los vv. 362 a 426 en la ed. de Domínguez Bordona, pero téngase en cuenta que este editor introduce ahí variantes respecto al texto del 42 que es el que paso a transcribir literalmente sin más que resolver abreviaturas.

${ }^{10}$ La edición de 1544 [desde ahora 44], que luego cito y comento en texto, da «a» respetando el correcto régimen verbal.

11 44: encomendemos

12 En 44 se lee: «es ave», mucho más de acuerdo, sin duda, con el original aunque este sabe también pueda aceptarse.

13 44: graue

14 44: quiera, más correctamente.

1544 : su, correctamente, y «buen» para el siguiente bien. 


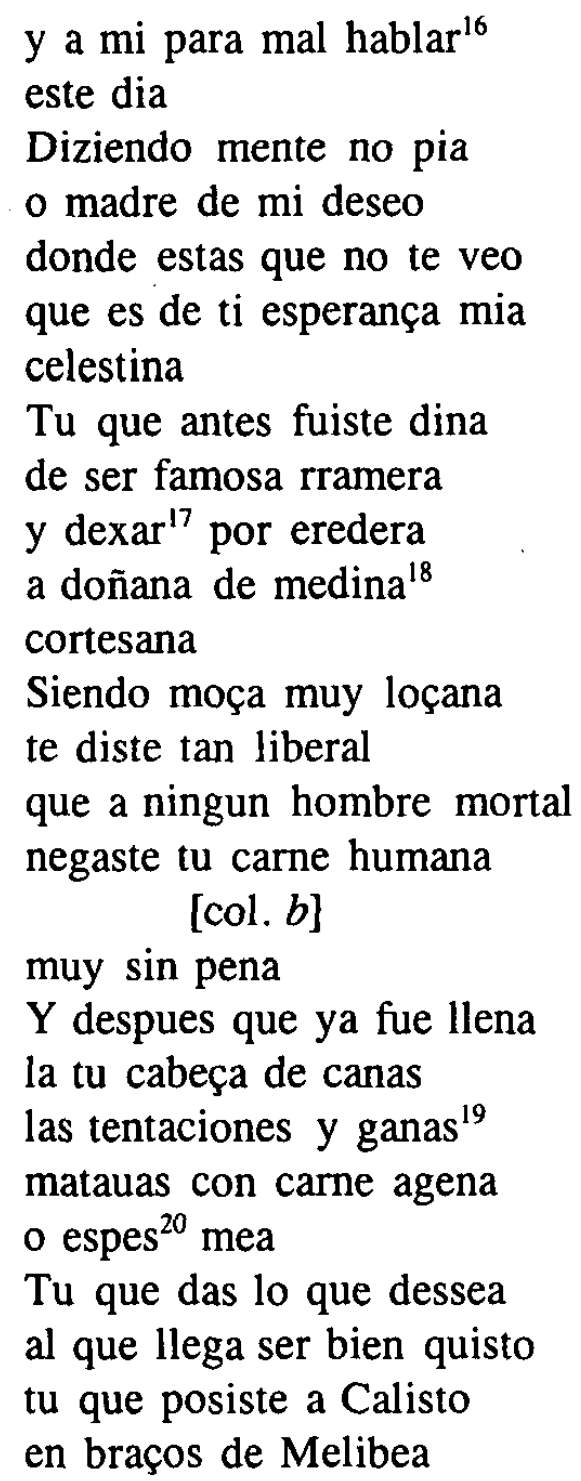

${ }^{16}$ Diego de San Pedro en el exordio inicial a su Sermon ordenado [...]porque dixeron unas señoras/que le desseauanoyr predicar, dice: "pongamos por medianera entre Amor y nosotros la Fe [...] porque nos alcance gracia, a mi para dezir, y a vosotras, señoras, para escuchar» (K. Whinnom, ed., Madrid, Castalia, I [1985], 173). Prueba ésta - y alguna otra más hay que aquí no corresponde citar - de que bien se conocía Castillejo a su Diego de San Pedro, como bien tambien se conocía su Celestina y a su Ovidio.

${ }^{17} 44$ : dexando

${ }^{18}$ Puta ya mencionada en la Carajicomedia, en copla XLV donde se dice de ella: «Ana de Medina es gentil mujer. Tiene sus beneficios en Burgos, paga diezmo de XXXV años al aguazil del obispo. ha sido muger de buen fregado, en la cual este miraglo oy en dia parece. Autores son mil legiones de carajos fríos y elados, y contrechos que alli han recebido perfeta curacion y escaldacion.»Cito por A. Alonso, ed., Carajiconiedia,Archidona (Málaga), Aljibe, 1995, p. 65.

\footnotetext{
${ }^{19} 44$ : y ganas, humanas

${ }^{20}$ Por ${ }^{*}$ spes.
} 
ven si quieres

Da luz ${ }^{21}$ a nuestros plazeres

haz que biua tu memoria

que es ya muerta ynes de soria ${ }^{22}$

espejo de las mugeres

tu priuada

Si tu ${ }^{23}$ estas alla ocupada

en essa region maldita

otra tal nos resucita ${ }^{24}$

entre la gente penada

que aca hierra

Danos vitoria en $1 a^{25}$ guerra

$\mathrm{y}$ virtud $^{26}$ con que podamos

gozar de quien desseamos

sobre la haz de la tierra

trabajosa

Ynfluye gracia amorosa

en esta empresa $\tan$ alta

que si duermes y nos falta

en tan importante cosa

tu fauor

Yo cuytado ${ }^{27}$ pecador

puta vieja que hare

madre mia adonde yre

que mal vezino es el amor

adonde $\mathrm{yre}^{28}$

${ }^{21}$ 44: lumbre, métricamente más correcto.

${ }^{22}$ En la citada Carajicomedia, y en copla XLVII se menciona a una Gudínez, leyéndose sobre ella en la glosa: «Es de saber que esta primera se llama Ines Gudínez, que es la más maldita puta vieja que ab inicio nació. D'esta es público que agora en sus postrimeros días, sellando su vida, cometió el más vil crimen que Celestina nunca hizo, y fue que vendió una hija suya a un fraile por ciertos dineros [...]» (p. 67); Inés como la que cita Castillejo, quizá sea la misma aunque ahí no se le aplica toponímico alguno.

${ }^{23} 44$ : Si tu, Y si

24 44: solicita

25 44: tal

${ }^{26} 44$ : y virtud con, señora por

27 44: mezquino

${ }^{28}$ Sin duda por error mecánico del cajista - se trata del paso de recto a vuelto del f. Aiiii - tras este verso se repite el anterior «que mal vezino es el amor», con ruptura, por exceso, de la quintilla. En el ms. del 44 no aparece este error, pero sí, curiosamente, el inverso. En efecto, ahí se omiten tanto «adonde yre» como el superfluo «que mal vezino es el amor» - sustituídos ambos por una línea horizontal 
Al examinar ahora la lista de referencias que J. Snow publicó en 1997 se puede comprobar, en efecto, que no fue Castillejo el primero en citar a Celestina, pero no menos que sí lo fue en caracterizarla con agudeza y acierto ya que entre todos los autores que ahí se recogen - y descontados, por supuesto, los que simplemente se limitaron a mencionar la obra - si alguno se le puede aproximar es, como mucho, el Pedro Manuel de Urrea de la Egloga de la tragicomediade Calisto y Melibea, pero los escasos trece versos con que este Urrea hace que Sempronio describa a la "vieja barbuda», ${ }^{29}$ lejos están en número $\mathrm{y}$ enjundia de todos esos sesenta y cinco que de Castillejo he transcrito. Enjundiosa y acertada caracterización que, por otra parte, y de atender a cierto significativo detalle, no parece que pasara inadvertida para más de uno de su tiempo.

En la portada que ilustra la edición de la Segunda comediade Celestina de Feliciano de Silva, impresa por Pedro de Castro en Salamanca en 1536, y como base de todo el grabado, aparece un amplio filete que representa a dos hombres que recogen del suelo a otro que ha caído de una escalera, ${ }^{30}$ filete que, como bien se ve, representa la caída y muerte de Calixto. Lo curioso es que el impresor del Sermón del 42 tuvo a bien, por su parte, incluir en el vuelto del último folio cierto grabado como colofón iconográfico que cerrara su trabajo; grabado, que es el de la reproducción adjunta y resulta ser exactamente el mismo que Pedro de Castro había usado antes para su portada. ${ }^{31}$ Perfectamente justificado como estaba dicho grabado para esa edición de la Segunda Celestina, el que asimismo se insertara en un Sermón que, en principio poco debía tener en común con la obra de Rojas ${ }^{32}$ buen índice es de todo lo celestinesco que se veía en esa composición castillejiana.

- dejando así truncada por defecto la correspondiente quintilla, y todo ello, precisamente, en el paso del f. $6^{v}$ a $7^{r}$.

${ }^{29}$ Pueden leerse en Brian Dutton, ed., El cancionerodelsigloXV: c. 1360-1520, 7 vols., Salamanca, Universidad, Biblioteca Española del siglo XV, 1990-1, VI: $72 a$.

${ }^{30}$ Puede verse reproducida esa portada en la ed. de C. Baranda, Madrid, Cátedra, 1988, p. 103.

${ }^{31}$ Esa identidad es, precisamente, la que, amén de algún otro detalle, ha llevado a Dennis E. Rhodes a postular que el «Sermón de amores» de 1542 salió de las prensas de Pedro de Castro cuando éste acababa de instalarse en Medina del Campo; cf. su artículo *The printing of the 'Sermón de amores' of Cristóbal de Castillejon, British Library Journal 13 (1987), 58-63, en donde se ve también reproducido el vuelto final del 42. E identidad que ya observó tambien Salvá cuando al describir ese ejemplar del Sermón anotó que lleva «la laminita que suele hallarse en las Celestinas» (loc.cit., col. $a)$.

${ }^{32}$ Sálvese aquí la respetable última opinión de Snow que, como sabemos, ha comenzado a dudar de tal paternidad. 
Volviendo ahora a dicha invocación en concreto, de señalar es que la misma no tuvo, que digamos, una existencia demasiado tranquila, que ciertos diversos avatares vino sufriendo tras su inicial aparición. Fue el primero el de una temprana versión que modifica, aumentándola, esa del 42. En la Biblioteca Nacional de Madrid obra una copia manuscrita [sign. Ms 22041] de dicho Sermón cuyo recto inicial reproduzco: «SERMON DE AMORES/ de el Maestro buen Talante/ llamado Frai Nidel de la/ Orden del Fristel agora/ nueuamente corregido, $\mathrm{y} /$ emendado.// In Quarto Letra gotica. // Impresso en la mui noble/ villa de Medina del Campo/ por Pedro de Castro/ Impressor de libros./ Acabose a ocho dias del/ mes de Hebrero. Año de/ 1544." ${ }^{33}$

El título, como se ve, es absolutamente idéntico al de la edición de 1542 , por lo que, en principio, podría sospecharse que el texto que ese copista tenía a la vista era simplemente una reimpresión que de ese 42 habría hecho Pedro de Castro dos años más tarde. La sospecha, sin embargo, se desvanece en cuanto se va al texto, pues este de 1544 no sólo presenta enorme profusión de variantes respecto a ese 42 - algunas de éstas ya las hemos visto antes sino que le añade unos casi seiscientos versos más, quince de los cuales aparecen intercalados, precisamente, dentro de esa invocación celestinesca. En efecto, en este 44 se lee toda la anterior del 42, pero entre los versos de ésta, «en brazos de Melibea» y «ven si quieres», inserta, además, los siguientes:

\author{
y escalaste \\ por amores y ganaste \\ muchas fortalezas \\ $\mathrm{y}$ adquiriste las riquezas \\ que en este mundo dexaste \\ y muriendo \\ por amor y padeciendo \\ martirio por el dinero \\ visitaste el canceruero \\ que tu inuocauas biuiendo \\ y tornada \\ al mundo con nueua estada \\ $\mathrm{y}$ con tus buenos ardides \\ constituiste a Felides
}

33 Siendo Pedro de Castro el impresor de este Sermón de 1544, el dato corrobora y reafirma lo sustentado por Rhodes - cf. $\mathrm{n} 31$ - de que fuera éste mismo el impresor del 42 . Hay que observar, además, la indudable importancia de la noticia que proporciona ese manuscrito, pues, que yo sepa, en ninguna de las bibliografias conocidas aparece recogida la existencia de esta edición de 1544 , edición que, como paso a señalar, presenta grandes diferencias con la anterior. 
con su gloria deseada ${ }^{34}$

Inserción que poco modifica la presentación de la personalidad de Celestina según aparecía expuesta ya en el anterior 42 , no haciendo sino ratificar lo reconocido ahí, sus interesadas actividades amorosas, su condición de avariciosa ave de rapiña y, finalmente, su muerte y correspondiente residencia «en essa region maldita" de la décima quintilla del primero. Pero inserción que, en cambio, sí nos presenta una interesante novedad, la de una Celestina resucitada, una Celestina «tornada/ al mundo con nueua estada». El lector que no estuviera demasiado al corriente de los últimos avatares celestinescos por los años treinta, hubiera podido considerar ingenioso, si no atrevido, que Castillejo se tomara tales libertades de resucitar, sin más, al personaje, pero no sería ese el caso para quien sí estuviera al tanto de lo que últimamente se cocía en ese ámbito, pues antes, y con todos los pertinentes honores, ya la había devuelto a la vida otro autor, el Feliciano de Silva que en 1534 había publicado su Segunda comedia de Celestina, un Feliciano de Silva que bien se había preocupado de exponer y elaborar esa resurrección, como uno de los motivos centrales de su obra a lo largo de las cenas VII a IX, para pasmo y sorpresa de sus otros portagonistas, si no lo fue tambien de los lectores. ${ }^{35}$

Y por supuesto que Castillejo no sólo fue uno de esos que al corriente de las novedades literarias de su tiempo sino que tan interesado estaba en la trayectoria literaria de Celestina que, incluso y amén de su resurrección, decidió incorporar también a su Sermón al nuevo principal personaje masculino con esos versos finales de "constituiste a Felides/ con su gloria deseada». Si sólo nos hubieran constado las trece quintillas del 42 con su genérica invocación y los específicos versos «tu que posiste a Calisto/ en brazos de Melibea», hubiera sido difícil poder atribuir a Castillejo más conocimiento textual que el de la primera Celestina, pero con el descubrimiento de este 44 y esos sus versos adicionales, comprobamos que si Castillejo conoció y disfrutó de la primera no menos hay que suponer que lo hizo con esa segunda de Feliciano de Silva. ${ }^{36}$

${ }^{34} \mathrm{La}$ inserción en f. $6^{v}$, cols. a-b.

${ }^{35}$ De que esa resurrección fue motivo central y un mucho de admirar algo nos dice que en el Cathalogus librorum qui prohibentur - el famoso índice de Valdés de 1559 - la obra apareciera no por su título sino, específicamente, como «Resurrection de Celestina." Cf. H. Reusch, Die Indices Librorum Prohibitorum des Sechzehnten Jahrhunderts, Nieuwkoop, B. de Graaf, 1970, p. 238.

${ }^{36}$ De que, además, todos estos datos abran la muy aceptable posibilidad de que Castillejo, para su Sermón, hubiera llevado a cabo distintas redacciones en diferentes años, es cuestión que no corresponde tratar aquí. 
Así las cosas, no puede decirse que la posterior reproducción de esa invocación tuviera demasiado éxito a lo largo de muchos años, y algo tuvieron que ver con ello ciertas circunstancias inquisitoriales.

Que sepamos, el Sermón - o, más propio será decir, parte de él - no volvió a editarse hasta 1573. En este año, Juan López de Velasco dió a luz pública las obras de Christoual de Castillejo. ${ }^{37}$ La edición, como ya indica la portada que he transcrito, apareció corregida y enmendada, correcciones y enmiendas que se ven justificadas y corroboradas en nota a final de texto, donde se lee:

El capítulo precedente del Amor y su poder, es fragmento, o parte de una obra que por cierto respecto parecio que no se deuia imprimir como estaua, y assi porque toda no se perdiesse se puso lo que della se pudo dexar en la forma que se ha puesto. (p. 263)

Y ciertamente "fragmento, o parte» es, y tanto que más bien se debería hablar de una edición corregidísima y enmendadísima, pues aparte de que este López de Velasco comenzó ya por rectificar el título original Sermón de amores, presentándolo como CAPITULO/ del Amor (203), si el citado manuscrito copia del 44 consta de 3347 vv., esta edición de 1573 contiene solamente 1621 - si no los he contado mal en uno y otro caso-, voluminosa reducción debida, claro está, a las muy varias y abundantísimas supresiones que con se infligió a la primera y entre las cuales se cuenta la de los vv. que en Domínguez Bordona van desde el 351 al 455 y que resultan ser los que, a su vez, contienen la invocación en cuestión.

Supresión que, por cierto, tuvo una larga y más bien persistente tradición. Esas Obras de Castillejo fueron reeditadas en Madrid por Francisco Sánchez en 1577, en Amberes, y en 1598, por Bellero y Nucio, y, por fin, y para acabar el XVII, por Andrés Sánchez, en Madrid, en 1600, pero siendo todas éstas, como fácilmente se puede comprobar, simples secuelas reeditoriales de la de López de Velasco: en ellas, lógicamente, se repite dicha mutilación.

Habrán de pasar casi dos siglos hasta que en 1792 D. Ramón Fernández, y en su Colección de poetas españoles (Madrid, en la Imprenta

${ }^{37}$ La portada de la edición - de los varios ejemplares que obran en la BNM, cito por U-1143 - reza: «LAS OBRAS DE/ CHRISTOVAL DE/ Castillejo/ CORREGIDAS, Y EMEN-/ dadas, por mandado del Consejo/ de la Santa, y general/ Inquisicion,/ IMPRESAS CON LICEN/ cia y priuilegio de su Magestad, pa/ ra los reynos de Castilla/ y Aragon./ En Madrid, por Pierres Cosin./ M. D. LXXIII.» 
Real), se decida a resucitar las Obras de Christobalde Castillejo en sus tomos XII y XIII, pero lo hace, no obstante, siguiendo al mismo castigado ${ }^{38} \mathrm{de} 1573$ con su título, Capítulo del amor, y en consecuencia con la correspondiente omisión.

Caso más destacable, por un tanto distinto a los anteriores, es el de Adolfo de Castro. En 1854, y en el tomo 32 de la BAE, Poetaslíricos de los siglos XVI y XVII, volvió a editar esas obras de Castillejo en pp. 105 a 252, y refiriéndose específicamente al Sermón, en nota a la p. 143, col. $a$, dice:

Se ha hecho todo lo posible por restaurar esta obrita, publicándola, si nono como salió de la pluma de su autor, al menos libre de las mutilaciones inquisitoriales.

Que, en principio, Castro sigue básicamente al 420 a un adiáforo suyo, resulta claro pues restituye el título original y, asimismo a diferencia del 73 , incorpora a su texto toda la introducción que el primero presenta y el segundo había omitido. No tan claro, ni mucho menos, que su texto saliera, como dice, «libre de las. mutilaciones inquisitoriales», porque lo cierto es que frente a los 3347 vv. del 44 , y aun los 2729 del 42 , su texto - y salvo error u omisión contiene solamente 1885 , no muchos más de los 1621 del 73 inquisitoriado, ${ }^{39}$

${ }^{38}$ Digo castigado remedando el sambenito que se le impuso al Lazarillo tras su publicación por el mismo López de Velasco que, como se sabe, lo editó conjuntamente con esas obras de Castillejo y la Propalladia de Torres Naharro en ese año de 1573.

39 Arremetiendo contra esa su tanto de arrogante y su mucho de falsa afirmación de Castro, dice Foulché-Delbosc: «Pour convaincre Castro d'inexactitude, il n'y a qu'à se reporter à l'édition originale du Sermón de amores, celle de 1542, qui fut reimprimée, mais expurgée, dans les oeuvres, en 1573, et que Castro ne connut pas. Le Sermón a 1885 vers dans l'édition de Castro: il en deux mille neuf cents dans l'édition originale!» (op.cit., 501). Y conste que con ello nos encontramos con un típico caso de alguacil alguacilado porque si algo se equivocaba Castro con su afirmación, un mucho de lo mismo se le puede aplicar a su crítico, ya que resulta excesivo afirmar tan tajantemente «que Castro ne connut pas» la edición del 42 , siendo que éste salpica continuamente su texto con variantes al pie referidas a «el original antiguo», «otras ediciones", «texto antiguo», etc., variantes que debidamente cotejadas se comprueba que corresponden a ese 42 o un adiáforo suyo, como acabo de decir. Por otra parte, es falso que «il en a deux mille neuf cents [versos] dans l'édition originale!» como tan ufanamente asegura, pues, para empezar, él mismo cometió en p. 588, el error de saltarse la numeración de los vv. desde el 2655 al 2670 - error que ya rectificó adecuadamente Domínguez Bordona dando los correspondientes $2890 \mathrm{vv}$. - y por otro lado, y como él mismo señala en nota (p. 620), el v. 2744 de su edición es el último de ese 42 original, no apareciendo en él ninguno de los restantes, restantes que, claro está, él tuvo que tomar - como ya ha dicho en $n .7$ - de ese mismo Castro contra quien 
no siendo, por tanto y obviamente, muchas menos que las de este 73 las supresiones que se dan en su edición. Y entre éstas, y concretamente, vienen a darse la de todos esos vv. desde el 351 al 455 que, a su vez, contienen la invocación.

Que López de Velasco los suprimiera, comprensible resulta, que sus razones y justificación tuvo para ello; que tambien lo hiciera Castro, no tanto, a pesar de sus alardes, y menos aún cuando, como se comprueba, tuvo a la vista si no todos ellos, sí, por lo menos, los de la susodicha invocación. En efecto, en p. 144 y en nota a la col. $b$, vemos que transcribe íntegros los últimos versos de la misma desde "Yo, cuitado pecador/», añadiendo algunos más de los que la siguen. ${ }^{40}$ ¿Qué razón o qué motivos tuvo para no insertar tal invocación en su edición aun teniéndola delante? Lo intenta explicar en la misma nota, donde respecto a tales versos dice: «No en todos los textos se hallan; lo cual me hace sospechar que tal vez fueron añadidos por alguno, como la introducción», inconsistente justificación donde las haya cuando se observa que, sin embargo, sí decide incluir en su texto tal introducción. Y más inconsistente y arbitraria todavía si se considera lo inaplicable que es a todos los otros cientos de versos que no incluyó. Obviamente, si los criterios inquisitoriales no producían muy buenos resultados cuando de editar un texto se trataba, no parece que los tan personales de Castro dieran mejores.

Y no que tuviera mucha más suerte la tal invocación para el resto del siglo pues si cierto es que en 1884 se volvió a publicar ese Sermón de Castillejo junto con su Diálogo de las mujeres, ${ }^{41}$ también lo es que dicha edición siguió a la de Castro en todos sus pormenores con, por tanto, la consiguiente omisión de la tan traída y llevada - o mejor diremos, poco publicada invocación.

Sólo, por fin y ya en el siglo $\mathrm{XX}$, se vio debidamente restituída - si bien, claro está, sin las tres quintillas del 44 - en la citada edición de Foulché-

arremete. ¡Así hicieron crítica textual algunos de nuestros antepasados!

40 Los que añade son los 427 a 441 de Domínguez Bordona. Significativamente, esos últimos versos que recoge de la invocación son los que contienen el verso superfluo que exclusivamente aparece en el 42 (comentado en n. 28), lo cual confirma definitivamente que Castro leía en él o en ese su correspondiente adiáforo.

${ }^{41}$ Madrid, Aribau, tomo XXXIX de la Biblioteca Universal. 
Delbosc, como asimismo, et pour cause, en la de Domínguez Bordona y en la última de $1999 .^{42}$

Como apostilla final, y puesto que de recopilar referencias sobre Celestina se trata, concluyo con la siguiente. En la BNM obra una colección de poesías manuscritas con el título genérico de Parnaso español. En el volumen 4 de la misma [MS 3915] - que hay que datar de entre finales del XVI y principios del XVII,$-^{43}$ en ff. 83 r. a $99^{v}$, se recoge una composición titulada Sátira contra unas monjas, extenso discurso en que cierta casada expone todas las ventajas de la vida monjil en comparación con la matrimonial. Sin duda obra de Fray Melchor de la Serna, ${ }^{44}$ en ella, y haciendo referencia a ciertas lecturas con que esas monjitas se deleitaban dentro de sus celdas, se recogen los siguientes vv. en folio $88^{r-v}$ :

que librillos alla de deuoçiones//

cuales sireno un tiempo componia

teniendo con siluano sus puntillos

${ }^{42}$ Cristóbal de Castillejo, Obra completa, edición e introducción de R. Reyes Cano, Madrid, Biblioteca Castro, 1999. Por cierto, que respecto a este específico Sermón, en esa introducción se lee que para él «hay que contar necesariamente [...]con el manuscrito 22041 de la misma biblioteca [la BNM]" (xxv) pero no parece que ése haya sido mucho el caso pues tal composición, que ahí corre desde pp. 179 a 255, sigue manteniendo los $2890 \mathrm{vv}$. de Domínguez Bordona. Avatar este último con el que se cierra la abundante serie de los que sufrió este Sermón de Castillejo, y avatares que, por otra parte, no fueron exclusivos en esta obra, que bastante análogos son los que vino a padecer otra suya, Diálogo de mujeres, como pueden verse expuestos por $\mathrm{R}$. Reyes Cano en su edición de 1986 (Madrid, Castalia) en pp. 50-52. Decididamente, no fue demasiado afortunado Castillejo con sus obras ni, como al principio he dicho, muy justamente tratado.

${ }^{43}$ En p. 11 del volumen aparece escrito: «De la mano y pluma de Jacinto López, músico de su majestad. En la villa de Madrid a veynte dias de de enero del año passado de mil y seyscientos y veynte.» y en la más extensa de las cuatro sátiras que ahí se recogen y es la que cito, se lee: «suenan los suspiros de sireno/ los melindres y selos de diana» $\left(87^{\circ}\right)$, y más adelante, «el estilo afectado con los nombres/ disfracados con siluias y belisas» $\left(88^{v}\right)$, amén de los vv. que doy en texto, ecos todos de las novelas pastoriles que desde la aparición de la Diana en 1559 tan en boga estuvieron precisamente por el último tercio del XVI.

${ }^{44} \mathrm{El} \mathrm{ms}$. de la BNM la presenta como anónima pero ya hace más de un siglo que el estudioso Julio Monreal vio identificado a su autor. En su trabajo "Votos y rejas», publicado en La ilustración española y americana, 1880, vol. 2, pp. 7, 10-11,27, 42-3, 46 y 58-9, tras incluir diversos trozos de dicha sátira, dice de ella: «Sátira en que habla una casadacon las monjas, del Padre Laserna, se halla inserta en tomo primero de una antología manuscrita que existe en la biblioteca de la Universidad literaria de Zaragoza» (p. 10, col. b, n7). 
alli de selestina(sic) ai sus ratillos otro de cortessano y de oriana con su amadis las ojas saltais todas.

A la serie de autores que a lo largo del XVI criticaron la perniciosa influencia de $L C$, y que ya recoge Snow en su lista, puede añadirse este Fray Melchor de la Serna.
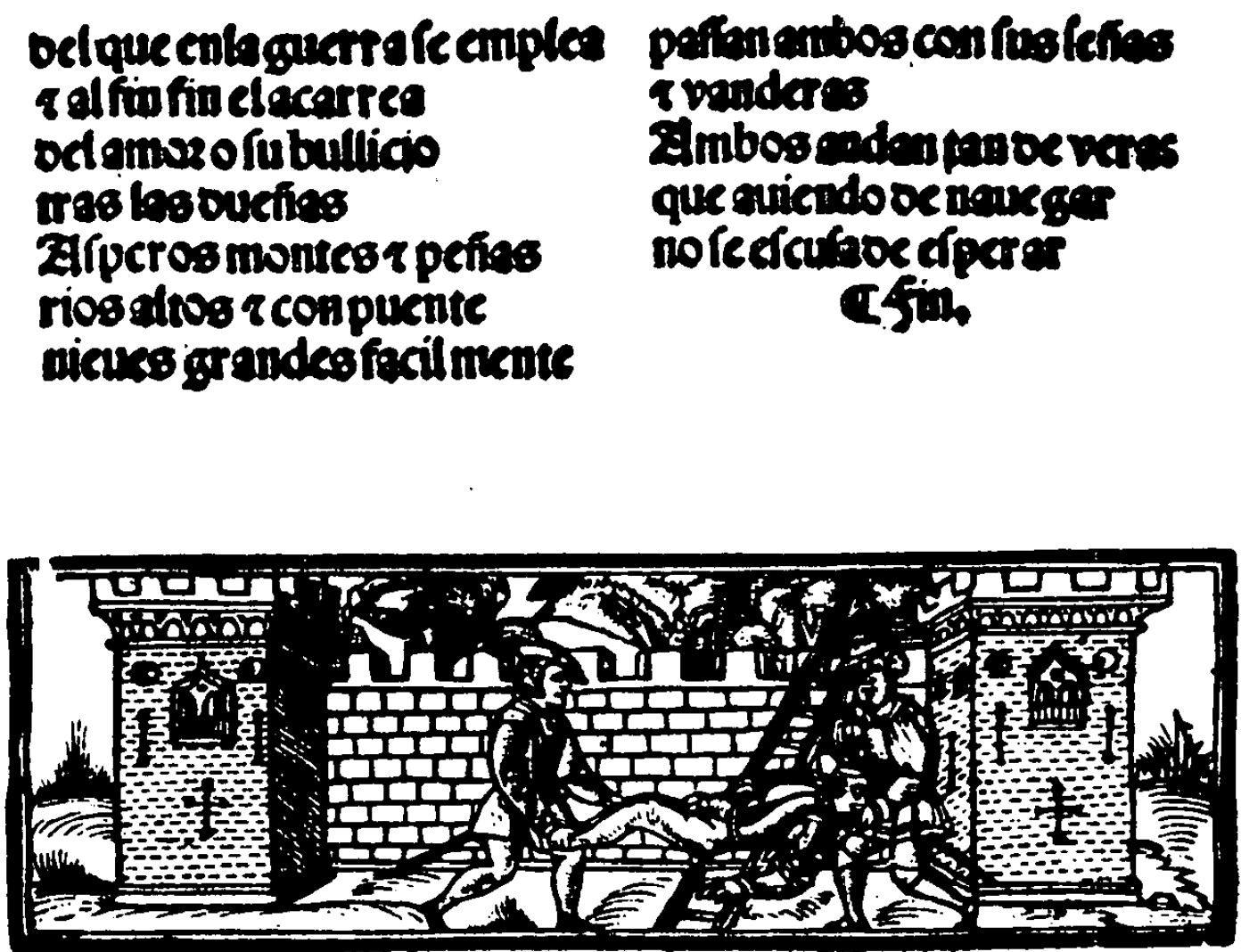

C. de Castillejo, Sermón de amores (1542)

(folio final, vuelto) 


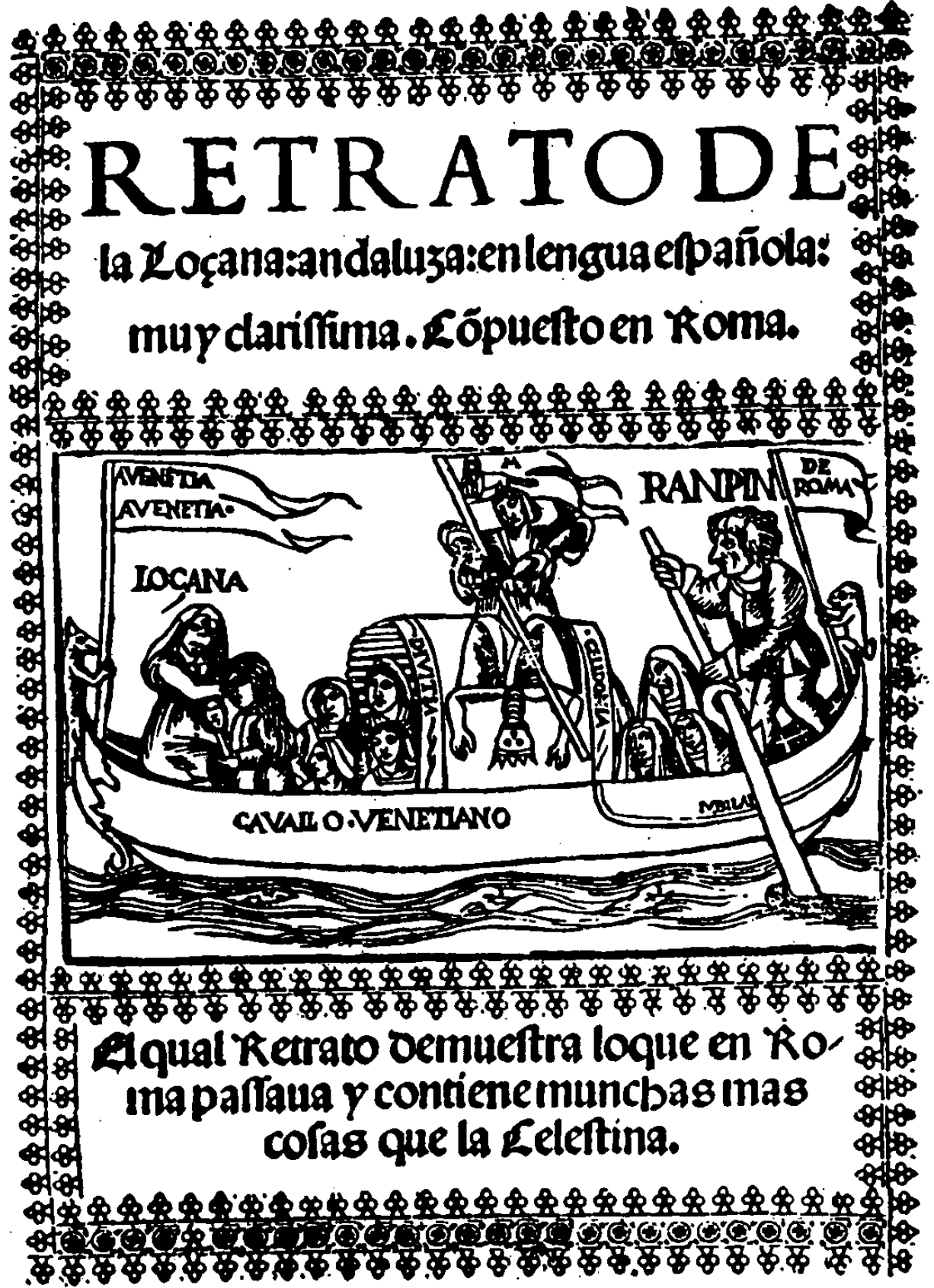

Portada. Lozana andaluza. 